Article

\title{
Defense Enzymes in Mycorrhizal Tomato Plants Exposed to Combined Drought and Heat Stresses
}

\author{
Imane Haddidi ${ }^{1}$, Nguyen Hong Duc ${ }^{1} \oplus$, Szende Tonk ${ }^{2} \oplus$, Eszter Rápó ${ }^{1,2}$ and $^{-}$ \\ Katalin Posta $1,3, *$ (D) \\ 1 Department of Genetics, Microbiology and Biotechnology, Szent István University, Páter Károly No. 1, \\ H-2100 Gödöllő, Hungary; microbiologieimen@outlook.com (I.H.); hongduc.real@gmail.com (N.H.D.); \\ rapo.eszter@phd.uni-szie.hu (E.R.) \\ 2 Environmental Science Department, Sapientia Hungarian University of Transylvania, Calea Turzii No. 4, \\ 400193 Cluj-Napoca, Romania; tonk.szende@sapientia.ro \\ 3 Institute of Biotechnology and Food Technology, Industrial University of Ho Chi Minh City, 12 Nguyen Van \\ Bao Street, Ho Chi Minh City 700000, Vietnam \\ * Correspondence: posta.katalin@mkk.szie.hu
}

Received: 24 September 2020; Accepted: 25 October 2020; Published: 28 October 2020

\begin{abstract}
As a result of climate change, drought and heat significantly reduced plant growth. Therefore, this study aims to explore and provide more insight into the effect of different arbuscular mycorrhizal fungi (AMF) strains (Rhizophagus irregularis, Funneliformis mosseae, and Funneliformis coronatum) on tomato plant tolerance against combined drought and heat stress, as well as combined drought and heat shock. A pot experiment was performed under controlled conditions in a growth chamber at $26 / 20{ }^{\circ} \mathrm{C}$ with a $16 / 8 \mathrm{~h}$ photoperiod. After six weeks of growth, one-third of plants were put in non-stress conditions, while another one-third were subjected to combined drought and heat stress ( $40 \%$ field capacity for two weeks and $38^{\circ} \mathrm{C} / 16 \mathrm{~h}$ and $30^{\circ} \mathrm{C} / 8 \mathrm{~h}$ for 5 days). The rest of the plants were exposed to combined drought and heat shock $\left(40 \%\right.$ of field capacity for two weeks and $45{ }^{\circ} \mathrm{C}$ for $6 \mathrm{~h}$ at the end of the drought period). All data were evaluated by one- and two-way analysis of variance (ANOVA). Means were compared by Duncan's post hoc test at $p<0.05$. The obtained results showed that combined drought and heat stresses had no significant impact on root colonization. Furthermore, stressed AMF plants exhibited a decrease in hydrogen peroxide and malondialdehyde content in the cells and showed changes in defense enzyme activities (peroxidase (POD), catalase (CAT), polyphenol oxidase (PPO), and glutathione S-transferase (GST)) in leaves as well as in roots compared with their relative non-mycorrhizal plants.
\end{abstract}

Keywords: arbuscular mycorrhizal fungi; ROS metabolism; antioxidative activity; simultaneous drought and heat stress; simultaneous drought and heat shock; tomato plant

\section{Introduction}

As sessile organisms, plants are frequently confronted with various unfavorable environmental conditions in their natural or agronomic habitats. The degradation of farmable lands caused by abiotic stresses, which represent the major limiting factors for agriculture, poses an earnest problem concerning food security [1-3]. Extreme temperature (heat) and drought stresses are major abiotic stresses that limit agricultural yield; they are interlinked as they co-occur in natural conditions. The Intergovernmental Panel on Climate Change reports that it is predicted that global temperature will rise by 1.5 to $4.5^{\circ} \mathrm{C}$ until the end of the current century [4]. Therefore, the negative effect of global warming on horticultural crop growth needs more attention.

Tomato (Solanum lycopersicum L.), with an annual production of 160 million tons, is one of the world's leading vegetables used not only in raw, but also processed form (almost 40 million tons of 
tomatoes annually). It is a critical horticultural crop that provides a wide range of necessary nutrients for human health. They are warm-season plants; therefore, the temperature has a considerable influence on its growth and development, where the ideal temperature is estimated to range between $20^{\circ} \mathrm{C}$ and $24{ }^{\circ} \mathrm{C}[5,6]$. Moreover, drought is a limiting factor in agriculture yield production; therefore, we can assume that the co-occurrence of these two abiotic stresses (drought and heat) can be more harmful $[4,7]$. It has been reported that the physiological and biochemical processes of plants are affected by combined stresses, as well as the photosynthesis and synthesis of protein and energy; moreover, it has a degrading effect on the ionic and osmotic balance, which induces oxidative stress in tomato plant [7].

The production of reactive oxygen species (ROS) is one of the most critical responses of the plant under heat and drought stresses, including superoxide anions $\left(\mathrm{O}_{2}^{-}\right)$, hydroxyl radical $(\mathrm{HO})$, and hydrogen peroxide $\left(\mathrm{H}_{2} \mathrm{O}_{2}\right)$ [8]. $\mathrm{ROS}$ are potentially responsible for oxidative stress, leading to deleterious damage of various structural and functional biological molecules compressing proteins, lipids, and nucleic acids [9-11]. Besides, ROS have a negative impact on photosynthesis and nutrient remobilization, and have the ability to trigger an irreversible senescence process [12]. ROS are likely considered to have a major link with plant growth and various stresses [13-16]. Hence, the plant has an antioxidant defense system to prevent oxidative stress consisting of several antioxidant enzymes such as superoxide dismutase (SOD); ascorbate peroxidase (APX); catalase (CAT) and glutathione reductase (GR); and non-enzymatic antioxidants like ascorbic acid, reduced glutathione (GSH), and tocopherol to scavenge excessive ROS [17,18].

Arbuscular mycorrhizal fungi (AMF) belonging to Phylum Glomeromycota are one of the most important microorganisms that form a symbiotic relationship with more than $80 \%$ of land plants $[19,20]$. Several studies have shown that AMF can enhance the growth of the host plant through improving soil structure, nutrient, and water uptake $[7,21,22]$. AMF are an important tool for neutralizing and alleviating peroxidative damage through increasing antioxidant enzyme activity [23-25]. Besides, Duc et al. [25] reported that AMF regulated plant physiology of the tomato plant to alleviate drought, heat stress by lowering lipid peroxidation level and $\mathrm{H}_{2} \mathrm{O}_{2}$ accumulation, and enhancing the efficiency of ROS scavengers (higher POD, SOD, and CAT activities) [25]. Recently, Huang et al. [9] showed that arbuscular mycorrhizal (AM) fungi could alleviate drought stress by increasing root $\mathrm{H}_{2} \mathrm{O}_{2}$ efflux in Trifoliate orange. Furthermore, other studies reported that AMF mediated host plant responses to drought stress through osmotic adjustments such as proline and sucrose accumulation, enhancing soil structure, or through the up-regulation of stress-responsive genes and induced changes in phytohormone abscisic acid (ABA) [18,23,26-28]. The effects of AMF on plant growth under drought and temperature stress conditions have been described in Leymus chinensis Hemarthria altissima [29], Solanum lycopersicum [25], and Elymus nutans [30].

Given the current and growing impacts of climate change, which amplify the amplitude and frequency of heat and drought shock (to which the field plants are simultaneously exposed), it is essential to develop a biotechnological method that focuses on enhancing defense enzymes of the plant with the introduction and reuse of beneficial natural soil microbiota. To the best of our knowledge, several studies have reported on the effect of single stress on tomato plants treated with AMF, while little is known about the combined effect of drought and heat, and more studies are required. In our previous study, we examined the effect of AMF on plant tolerance to individual drought or heat shock, and combined drought and heat shock [25]. Our results showed that the combined drought and heat shock caused more severe damage to tomato plants than individual stresses, but AMF alleviated the negative impacts of the single stresses and the combined stress. We expanded the experiment with combined drought and heat stress together with combined drought and heat shock based on our previous results. However, in this study, we only focused on two combinations of drought and heat that frequently occur in field conditions and climate change. From our viewpoint, research on combinations of these stresses is more realistic because multiple stresses take place in general under field cultivation. We support the point that combined stresses (combined drought and heat stresses in 
our study) are unique and more natural. Therefore, the main goal of the current study is to clarify and understand the role of AM symbiosis on ROS metabolism and the antioxidative activity of tomato plants under combined drought and heat, as well as drought and heat shock, and to investigate an economically and ecologically potential way to make agriculture more resilient.

\section{Materials and Methods}

\subsection{Substrate and Biological Materials}

Solanum lycopersicum (L.) var. MoneyMaker seeds (Sieberz Ltd., Gödöllő, Hungary) were surface sterilized by immersion into $2.5 \%$ sodium hypochlorite containing $0.02 \%(v / v)$ Tween-20 for $30 \mathrm{~min}$, then seeds were washed several times with sterile distilled water for $10 \mathrm{~min}$. Seeds were germinated on moist filter paper in Petri dishes for 3 days at room temperature. The pre-germinated seeds were sown in plastic pots containing $0.5 \mathrm{~kg}$ of sterilized sand and peat mixture $(4: 1, v / v)$.

\subsection{Arbuscular Mycorrhizal Fungal Inoculum}

Three different mycorrhizal fungal inocula, Funneliformis mosseae (collection of Szent István University), Rhizophagus irregularis USK F1 (collection of the University of Silesia in Katowice), and Funneliformis coronatum (Giovann.), originated from Prof. Janusz Blaszkowski (Department of Plant Protection, West Pomeranian University of Technology, Szczecin, Poland), were used. All strains were cultured with Zea mays (L.) and Plantago lanceolata (L.) separately for five months in sterilized sand. The crude inoculum consisted of sand, spores, mycelium, and infected root fragments. Each pot was inoculated with $50 \mathrm{~g}\left(20\right.$ spores $\left.\mathrm{g}^{-1}\right)$ inoculum for each mycorrhizal treatment. In addition, to ensure the general microbial population in the soil and avoid mycorrhizal propagules, the non-AM plants were prepared with the same proportion of autoclaved inocula substrate together with $3 \mathrm{~mL}$ aliquot of AMF inocula filtrate $(<20 \mu \mathrm{m})$ [31]. For each treatment, the inoculums were applied $4 \mathrm{~cm}$ below the depth of seeding in each pot.

\subsection{Growth Conditions and Experimental Design}

Plants were randomly distributed and grown in a climatic chamber with $600 \mu \mathrm{mol} \mathrm{m} \mathrm{m}^{-2} \mathrm{~s}^{-1}$ photon flux density, at $26 / 20^{\circ} \mathrm{C}$, with $16 / 8$ hours' day/night temperature and $60 \%$ relative humidity at Institute of Genetics, Microbiology, and Biotechnology, Szent István University, Gödöllő, Hungary.

Experiments were carried out in eight replicates for four tomato treatments: control sample, where the plants were not inoculated with AMF (No AM); plants inoculated with R. irregularis; plants inoculated with F. mosseae; and plants inoculated with F. coronatum. For all four tomato treatments, a total of 96 pots were used, where three stress effects were examined: control with $100 \%$ field capacity, no stress (NoS); simultaneous heat and drought stress $(\mathrm{D}+\mathrm{H})$; and simultaneous drought and heat shock stress (D + HS). All plants were grown under the same non-stress conditions for six weeks, after which different stress applications were implemented (Figure S1). First of all, 32 pots were kept in non-stress conditions (growing conditions described above), while drought stress was applied for 64 pots. Drought stress was achieved by watering the plants at $40 \%$ field capacity for 14 days. Half of the drought pots (32 pots) were exposed to high temperature, that is, $38^{\circ} \mathrm{C}$ for $16 \mathrm{~h}$ during the daytime and $30^{\circ} \mathrm{C}$ for $8 \mathrm{~h}$ at night for the last 5 days of the experiment (from day 9, till day 14 of the drought period), while relative humidity and light intensity remained the same as in non-stress conditions. The rest of the drought pots (32 pots) were subjected to even higher temperature conditions (heat shock) at $45^{\circ} \mathrm{C}$. This took place only for $6 \mathrm{~h}$ before the plants were harvested.

Plants were harvested at the end of the combined stress applications (14 days after the start of drought stress). Fully expanded leaves and root samples were immediately frozen in liquid nitrogen and stored at $-80^{\circ} \mathrm{C}$ until further analysis. 


\subsection{Assessment of Tomato Plant Biomass}

Four plants for each treatment were used for the estimation of fresh plant biomass.

\subsection{Root Colonization by AMF}

Root colonization by AMF was studied with the visual inspection method, where a stereomicroscope was used at $100 \times$ magnification [32,33]. A total of sixty $(1 \mathrm{~cm}$ long) root pieces were randomly selected from both non-AM and AM plants from each condition (NoS, D + H, D + HS), after which they were cleaned with $10 \% \mathrm{KOH}$ for $10 \mathrm{~min}$, followed by the acidification of the segments with $2 \%$ hydrochloric acid and $0.05 \%$ trypan blue (1:1:1 proportion of water/glycerol/lactic acid), and left overnight [32]. The mycorrhizal colonization ratio was calculated by the gridline intersection method [33].

\subsection{Determination of $\mathrm{H}_{2} \mathrm{O}_{2}$ Content}

Hydrogen peroxide $\left(\mathrm{H}_{2} \mathrm{O}_{2}\right)$ concentration in leaves and roots was measured by the U-2900 UV-VIS spectrophotometer (Hitachi) at $390 \mathrm{~nm}$ [34]. Here, $0.5 \mathrm{~g}$ frozen (leaf/root) sample was grounded with liquid $\mathrm{N}_{2}$ to obtain a homogeneous, fine powder. After that, $5 \mathrm{~mL}$ of cold $0.1 \%(w / v)$ trichloroacetic acid (TCA) kept in an ice bath was added and the obtained solution was centrifuged at $12,000 \times g$ for $15 \mathrm{~min}$ at $4{ }^{\circ} \mathrm{C}$. Next, $0.5 \mathrm{~mL}$ of the supernatant was added to $0.5 \mathrm{~mL}$ of $100 \mathrm{mM}$ potassium phosphate buffer ( $\mathrm{pH} 7.0$ ) and $1 \mathrm{~mL}$ of $1 \mathrm{M}$ iodic potassium (KI). The reaction occurred for $1 \mathrm{~h}$ in darkness at room temperature.

\subsection{Determination of Malondialdehyde (MDA) Content}

The lipid peroxidation level was determined by homogenizing $0.2 \mathrm{~g}$ of (leaf/root) sample in $5 \mathrm{~mL} 0.1 \%$ TCA, then the mixture was centrifuged at 10,000 $\mathrm{g}$ for $5 \mathrm{~min}$ [35]. Then, $1 \mathrm{~mL}$ of the previously centrifuged supernatant was mixed with $4 \mathrm{~mL}$ of $20 \%$ TCA containing $0.5 \%$ thiobarbituric acid (TBA). The solution was heated in a water bath $\left(95^{\circ} \mathrm{C}\right)$ for $15 \mathrm{~min}$, then immediately cooled in an ice bath [25]. MDA was calculated based on absorbances at $532 \mathrm{~nm}$ and $600 \mathrm{~nm}$ using a double beam spectrophotometer. Lipid peroxidation level was expressed in nmol MDA amount, where the extinction coefficient was $155 \mathrm{mM}^{-1} \mathrm{~cm}^{-1}$.

\subsection{Defense Enzymatic Activity Determination}

Here, $0.5 \mathrm{~g}$ of frozen tomato leaf and root samples was placed in a pre-cooled sterile mortar and homogenized in liquid nitrogen $\left(\mathrm{N}_{2}\right)$ together with $3 \mathrm{~mL}$ Tris- $\mathrm{HCl}$ buffer $(50 \mathrm{mM}, \mathrm{pH} 7.8)$ containing $7.5 \%(w / v)$ polyvinyl-pyrrolidone $\mathrm{K} 25$ and $1 \mathrm{mM}$ Ethylenediaminetetraacetic acid disodium salt dihydrate $\left(\mathrm{Na}_{2}\right.$ EDTA). The solution was centrifuged for $20 \mathrm{~min}$ at $4{ }^{\circ} \mathrm{C}$ at $10,000 \times g$. The supernatant was further used to measure enzyme activities such as peroxidase, polyphenol oxidase, catalase, and glutathione S-transferases. Until further use, samples were kept in a freezer. A double beam spectrophotometer (Hitachi U-2900 UV-VIS) was used to determine enzyme activities.

\subsubsection{Glutathione S-Transferase}

Glutathione S-transferase (GST, EC 2.5.1.18) activity was determined using an assay kit purchased from Sigma-Aldrich, Missouri, USA (product identification: CS0410). The reaction mixture contained substrate solution $(980 \mu \mathrm{L}$ Dulbecco's phosphate buffer saline, $10 \mu \mathrm{L}$ of $200 \mathrm{mM}$ L-Glutathione reduced, and $10 \mu \mathrm{L}$ of $100 \mathrm{mM}$ 1-Chloro-2,4-dinitrobenzene (CDNB) with $2 \mu \mathrm{L}$ of plant extract. As described by Habig et al., the absorbance of the solution was measured for $5 \mathrm{~min}$ at $340 \mathrm{~nm}$ [36]. GST activity was expressed in $\mu \mathrm{mol} \mathrm{ml}^{-1} \mathrm{~min}^{-1}$, where the extinction coefficient for CDNB conjugate at $340 \mathrm{~nm}$ was $9.6 \mathrm{mM}^{-1} \mathrm{~cm}^{-1}$. 


\subsubsection{Catalase}

Catalase (CAT, EC 1.11.1.6) activity was measured using a Catalase assay kit purchased from Sigma-Aldrich, St. Louis, MO, USA (product identification: CAT 100). The activity was measured for the solution containing $5 \mu \mathrm{L}$ of plant extract mixed with $500 \mu \mathrm{L} 1 \mathrm{X}$ assay buffer and $500 \mu \mathrm{L} \mathrm{H}_{2} \mathrm{O}_{2}$ $(20 \mathrm{mM})$, and the degradation of hydrogen peroxide was monitored and recorded at $240 \mathrm{~nm}$ wavelength for $5 \mathrm{~min}$.

\subsubsection{Peroxidase}

Peroxidase (POD, EC 1.11.1.7) activity was assessed as the protocol of Rathmell and Sequeira [37]. Solution preparation: $10 \mu \mathrm{L}$ plant extract was mixed with the reaction mixture $2.2 \mathrm{~mL}(0.1 \mathrm{M}$ sodium phosphate buffer (pH 6.0), $100 \mu \mathrm{L}$ of $12 \mathrm{mM} \mathrm{H}_{2} \mathrm{O}_{2}$, and $100 \mu \mathrm{L}$ of $50 \mathrm{mM}$ guaiacol). Similar to the other enzyme amount measurements, the spectrophotometric determination was done at $436 \mathrm{~nm}$ for $5 \mathrm{~min}$. The enzyme activity was calculated by the changes in absorbance. POD activity was expressed in $\mathrm{mmol} \mathrm{mL} \mathrm{min}^{-1}$, where the extinction coefficient was $25.5 \mathrm{mM}^{-1} \mathrm{~cm}^{-1}$.

\subsubsection{Polyphenol Oxidase}

Polyphenol oxidase (PPO, EC 1.10.3.1) activity was measured by the modified procedure of Fehrmann and Dimond [38]. The assay mixture contained $2.2 \mathrm{~mL}$ reaction mixture $(0.1 \mathrm{M}$ sodium phosphate buffer ( $\mathrm{pH}$ 6.0), $1 \mathrm{mM} \mathrm{Na}_{2}$ EDTA, and $20 \mathrm{mM}$ catechol) with $100 \mu \mathrm{L}$ of plant extract. The degree of quinone formation was recorded at $400 \mathrm{~nm}$ wavelength in $5 \mathrm{~min}$. Furthermore, PPO activity was expressed in $\mu \mathrm{mol} \mathrm{mL} \mathrm{mmin}^{-1}$, where the extinction coefficient was $1150 \mathrm{M}^{-1} \mathrm{~cm}^{-1}$.

\section{Results}

\subsection{Plant Growth and Mycorrhizal Colonization}

Under no stress conditions, a similar trend was observed on fresh plant weight for both AM and non-AM plants. Moreover, both mycorrhiza and stress application significantly affected fresh plant biomass, and the interaction between them was also significant (Table 1).

Table 1. Effects of arbuscular mycorrhizal (AM) inoculation (M), stress application (S), and the interaction between $\mathrm{M}$ and $\mathrm{S}$ on the measured parameters. POD, peroxidase; CAT, catalase; PPO, polyphenol oxidase; GST, glutathione S-transferase; MDA, malonaldehyde.

\begin{tabular}{|c|c|c|c|c|c|}
\hline Parameters & Variables & Mean Squares & F-Value & $D_{f}$ & $p$-Value \\
\hline \multirow{3}{*}{ Fresh shoot biomass } & AM inoculation (M) & 4.548 & 7.42 & 3 & $* * 0.0006$ \\
\hline & Stress application (S) & 131.045 & 213.85 & 2 & $* * *<0.0001$ \\
\hline & $M * S$ & 3.819 & 6.23 & 6 & $* * 0.0002$ \\
\hline \multirow{3}{*}{ Leaf $\mathrm{H}_{2} \mathrm{O}_{2}$ accumulation } & AM inoculation (M) & 4.991 & 18.09 & 3 & $* * *<0.0001$ \\
\hline & Stress application (S) & 114.779 & 415.85 & 2 & $* * *<0.0001$ \\
\hline & $M * S$ & 2.26 & 8.19 & 6 & $* * *<0.0001$ \\
\hline \multirow{3}{*}{ Root $\mathrm{H}_{2} \mathrm{O}_{2}$ accumulation } & AM inoculation (M) & 0.7 & 13.07 & 3 & $* * *<0.0001$ \\
\hline & Stress application (S) & 3.894 & 72.67 & 2 & $* * *<0.0001$ \\
\hline & $M * S$ & 0.551 & 10.28 & 6 & $* * *<0.0001$ \\
\hline \multirow{3}{*}{ Leaf MDA } & AM inoculation (M) & 0.152 & 19.89 & 3 & $* * *<0.0001$ \\
\hline & Stress application (S) & 1.081 & 140.73 & 2 & $* * *<0.0001$ \\
\hline & $M * S$ & 0.074 & 9.74 & 6 & $* * *<0.0001$ \\
\hline \multirow{3}{*}{ Root MDA } & AM inoculation (M) & 0.002 & 5.3413 & 3 & $* * 0.0037$ \\
\hline & Stress application (S) & 0.012 & 30.1518 & 2 & $* * *<0.0001$ \\
\hline & $M^{*} S$ & 0.002 & 5.7469 & 6 & $* * *<0.0001$ \\
\hline \multirow{3}{*}{ Leaf CAT } & AM inoculation (M) & 3752.957 & 12.44 & 3 & $* * *<0.0001$ \\
\hline & Stress application (S) & $20,880.46$ & 69.23 & 2 & $* * *<0.0001$ \\
\hline & $M * S$ & 1688.4 & 5.6 & 6 & $* * *<0.0001$ \\
\hline
\end{tabular}


Table 1. Cont.

\begin{tabular}{|c|c|c|c|c|c|}
\hline Parameters & Variables & Mean Squares & F-Value & $D_{f}$ & $p$-Value \\
\hline \multirow{3}{*}{ Root CAT } & AM inoculation (M) & 1951.394 & 12.46 & 3 & $* * *<0.0001$ \\
\hline & Stress application (S) & $16,928.51$ & 108.05 & 2 & $* * *<0.0001$ \\
\hline & $\mathrm{M}^{*} \mathrm{~S}$ & 1110.936 & 7.09 & 6 & $* * *<0.0001$ \\
\hline \multirow{3}{*}{ Leaf POD } & AM inoculation (M) & 346.791 & 15.76 & 3 & $* * *<0.0001$ \\
\hline & Stress application (S) & 6526.13 & 296.5 & 2 & $* * *<0.0001$ \\
\hline & $\mathrm{M}^{*} \mathrm{~S}$ & 202.406 & 9.2 & 6 & $* * *<0.0001$ \\
\hline \multirow{3}{*}{ Root POD } & AM inoculation (M) & 2609.255 & 23.94 & 3 & $* * *<0.0001$ \\
\hline & Stress application (S) & $19,807.52$ & 181.7 & 2 & $* * *<0.0001$ \\
\hline & $\mathrm{M}^{*} \mathrm{~S}$ & 1465.06 & 13.44 & 6 & $* * *<0.0001$ \\
\hline \multirow{3}{*}{ Leaf PPO } & AM inoculation (M) & 0.003 & 6.96 & 3 & $* * *<0.0001$ \\
\hline & Stress application (S) & 0.08 & 155.71 & 2 & $* * *<0.0001$ \\
\hline & $M^{*} S$ & 0.001 & 2.21 & 6 & *0.0155 \\
\hline \multirow{3}{*}{ Root PPO } & AM inoculation (M) & 0.002 & 9.76 & 3 & $* * *<0.0001$ \\
\hline & Stress application (S) & 0.083 & 297.48 & 2 & $* * *<0.0001$ \\
\hline & $M^{*} S$ & 0.002 & 8.39 & 6 & $* * *<0.0001$ \\
\hline \multirow{3}{*}{ Leaf GST } & AM inoculation (M) & 0.054 & 3.59 & 3 & $* * 0.0023$ \\
\hline & Stress application (S) & 0.244 & 16.02 & 2 & $* * *<0.0001$ \\
\hline & $M^{*} \mathrm{~S}$ & 0.092 & 6.05 & 6 & $* * *<0.0001$ \\
\hline \multirow{3}{*}{ Root GST } & AM inoculation (M) & 0.043 & 2.62 & 3 & $* 0.0185$ \\
\hline & Stress application (S) & 0.52 & 31.37 & 2 & $* * *<0.0001$ \\
\hline & $M^{*} \mathrm{~S}$ & 0.045 & 2.77 & 6 & $* * 0.0026$ \\
\hline
\end{tabular}

$*, * *$, and ${ }^{* * *}$ indicate significant differences at $p<0.05,0.01$, and 0.001 , respectively.

The fresh shoot biomass was reduced under imposed stresses compared with the NoS condition (Table 2), with almost $32 \%$ of all plants subjected to D $+\mathrm{H}$, while it decreased by $29 \%$ under D + HS for root colonized by $R$. irregularis and F. coronatum. In contrast, plants inoculated by F. mosseae did not change the biomass as compared with the corresponding non-stress condition.

Table 2. Fresh plant biomass and AM colonization rate in plants not inoculated or inoculated by $R$. irregularis, F. mosseae, or F. coronatum under no stress, drought + heat stress, and drought + heat shock after eight weeks of growth.

\begin{tabular}{cccc}
\hline Stress Condition & AM Inoculation & Fresh Plant Biomass (g plant $\mathbf{~}^{-1}$ ) & AM Colonization (\%) \\
\hline \multirow{3}{*}{ No stress } & No AM & $17.21 \pm 0.33 \mathrm{Aa}$ & 0 \\
& R. irregularis & $17.86 \pm 0.84 \mathrm{Aa}$ & $58.87 \pm 6.90$ \\
& F. mosseae & $17.17 \pm 1.41 \mathrm{Aa}$ & $47.27 \pm 7.35$ \\
& F. coronatum & $17.23 \pm 1.37 \mathrm{Aa}$ & $48.01 \pm 7.11$ \\
\hline \multirow{2}{*}{ Drought + heat } & No AM & $11.38 \pm 0.43 \mathrm{Bb}$ & 0 \\
stress & R. irregularis & $12.28 \pm 0.66 \mathrm{Ba}$ & $63.82 \pm 11.47$ \\
& F. mosseae & $12.02 \pm 0.89 \mathrm{Ba}$ & $53.16 \pm 6.44$ \\
& F. coronatum & $11.79 \pm 0.59 \mathrm{Bba}$ & $48.36 \pm 9.07$ \\
Drought + heat & No AM & $12.31 \pm 0.34 \mathrm{Cb}$ & 0 \\
shock & R. irregularis & $12.75 \pm 1.12 \mathrm{Bb}$ & $52.09 \pm 9.45$ \\
& F. mosseae & $15.72 \pm 0.46 \mathrm{Aa}$ & $55.84 \pm 8.14$ \\
& F. coronatum & $12.18 \pm 0.47 \mathrm{Bb}$ & $51.03 \pm 7.93$ \\
\hline
\end{tabular}

AM, arbuscular mycorrhizal. No AM, without arbuscular mycorrhiza. For each parameter, the means \pm standard deviations are presented $(n=4)$. Different minuscule within a column indicates significant differences among treatments under the same conditions (no stress, drought + heat stress, or drought + heat shock) by Duncan's post hoc test at $p \leq 0.05$. Different capital letters within a column indicate significant differences of the same treatments (No AM, R. irregularis, F. mosseae, or F. coronatum) under different conditions (no stress, drought + heat stress, and drought + heat shock) by Duncan's post hoc test at $p \leq 0.05$.

The assessment of root colonization under microscopic examinations showed a good symbiotic association between different arbuscular mycorrhizal species and tomato plant roots. No mycorrhizal colonization could be detected in the roots of non-mycorrhizal plants. Moreover, no significant 
differences in the colonization rates of plant inoculated with three AMF inoculums were detected following various stress treatments. The highest percentage of mycorrhization reached $63.82 \%$ in plants treated with $R$. irregularis under D $+\mathrm{H}$ and $55.84 \%$ in plants inoculated with F. mosseae under D + HS.

\subsection{Accumulation of Hydrogen Peroxide and Lipid Peroxidation}

$\mathrm{D}+\mathrm{H}$ and $\mathrm{D}+\mathrm{HS}$ significantly increased the generation of $\mathrm{H}_{2} \mathrm{O}_{2}$ in tomato plants, leading to considerable oxidative damage, which can be measured as malonaldehyde (MDA) content. Under NoS condition, no significant difference was observed in the $\mathrm{H}_{2} \mathrm{O}_{2}$ amount for tomato leaves: $\mathrm{No} \mathrm{AM}=3.06 \pm 0.46 \mathrm{nmol} \mathrm{g}^{-1} \mathrm{FW}, R$. irregularis $=2.38 \pm 0.48 \mathrm{nmol} \mathrm{g}{ }^{-1} \mathrm{FW}, F$. mosseae $=2.39 \pm 0.40 \mathrm{nmol} \mathrm{g}^{-1} \mathrm{FW}$, and F. coronatum $=2.96 \pm 0.70 \mathrm{nmol} \mathrm{g}{ }^{-1} \mathrm{FW}$ (Figure 1A). However, significant increases in leaf and root $\mathrm{H}_{2} \mathrm{O}_{2}$ content were detected in plants without AM inoculation only under stress conditions ( $\mathrm{D}+\mathrm{H}, \mathrm{D}+\mathrm{HS})$. AM treatment significantly $(p<0.0001)$ reduced $\mathrm{H}_{2} \mathrm{O}_{2}$ concentration compared with that of non-AM plants (Table 1, Figure 1). In detail, plants inoculated with $\mathrm{F}$. mosseae showed a considerably lower $\mathrm{H}_{2} \mathrm{O}_{2}$ accumulation in leaves under $\mathrm{D}+\mathrm{H}$ stress relative to non-mycorrhizal ones (reduced by $35 \%$ ), for plants inoculated by both R. irregularis and F. coronatum, where the $\mathrm{H}_{2} \mathrm{O}_{2}$ decreased by $20 \%$. Under $\mathrm{D}+\mathrm{HS}$, no significant differences in $\mathrm{H}_{2} \mathrm{O}_{2}$ levels were observed among the three AMF species (R. irregularis, F. mosseae, and F. coronatum), where AMF species reduced $\mathrm{H}_{2} \mathrm{O}_{2}$ levels in leaves by almost $23 \%$ compared with no AMF under D + HS.
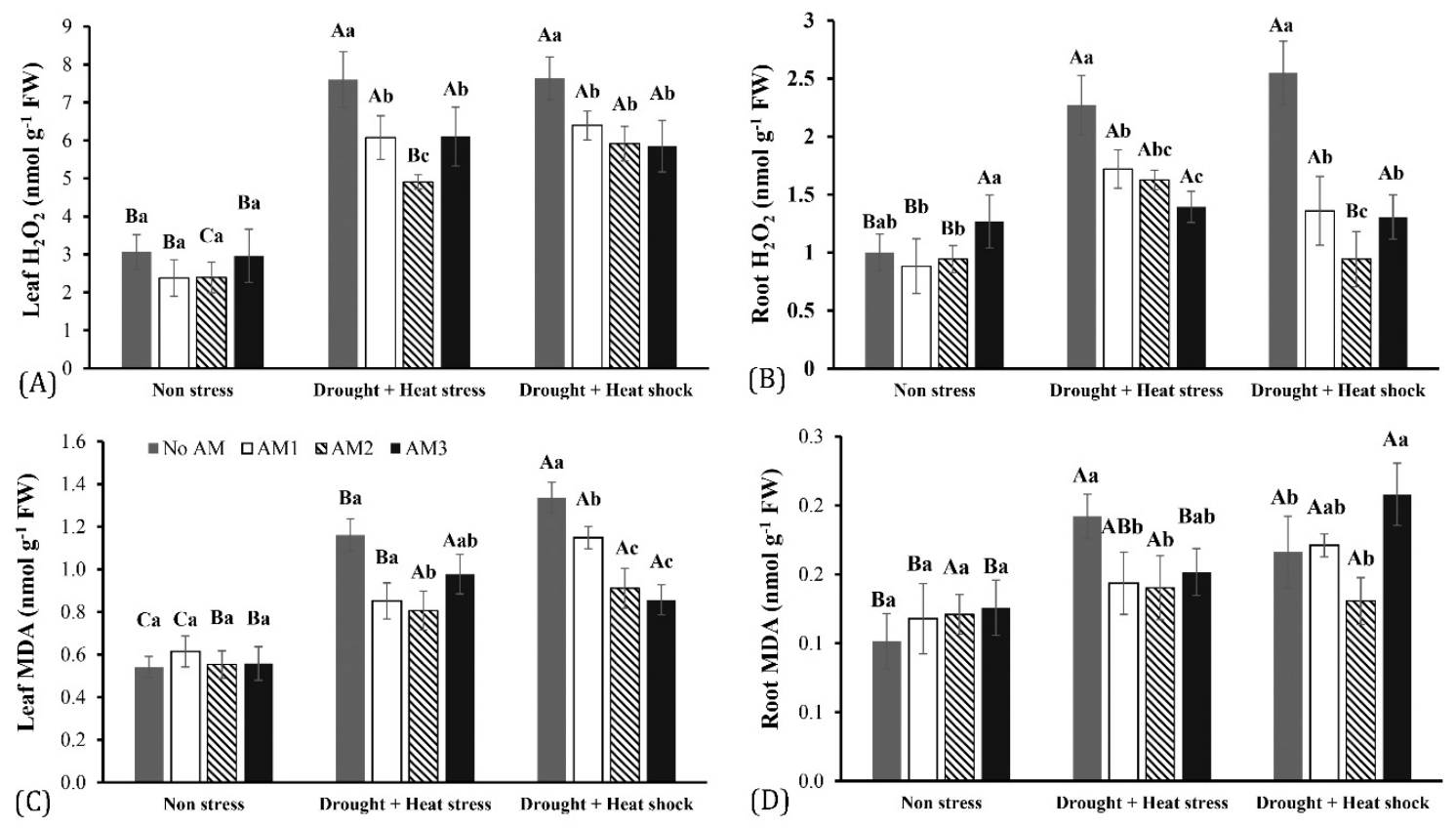

Figure 1. Hydrogen peroxide $\left(\mathrm{H}_{2} \mathrm{O}_{2}\right)$ and malonaldehyde (MDA) accumulation in leaves $(\mathbf{A}, \mathbf{C})$ and roots (B,D) of non-inoculated plants (No arbuscular mycorrhizal (AM) and plants inoculated by R. irregularis (AM1), F. mosseae (AM2), or F. coronatum (AM3) subjected to non-stress (NoS), drought + heat stress, and drought + heat shock. Each bar represents the mean and standard deviation $(n=4)$. Different minuscules indicate significant difference among treatments under the same conditions (no stress, drought + heat stress, or drought + heat shock) by Duncan's post hoc test at $p \leq 0.05$. Different capital letters indicate significant differences of the same treatments (No AM, R. irregularis, F. mosseae, or F. coronatum) under different conditions (no stress, drought + heat stress, and drought + heat shock) by Duncan's post hoc test at $p \leq 0.05$.

In roots, there were significant $(p<0.0001)$ main effects of AM inoculation, stress application, and their interaction on root $\mathrm{H}_{2} \mathrm{O}_{2}$ accumulation (Table 1). The level of hydrogen peroxide was significantly higher in non-AM plants than in AM plants (increased by almost 61\%) under imposed stresses (D + H, D + HS) 
in comparison with no stress conditions and was significantly decreased in inoculated plants. In $\mathrm{D}+\mathrm{H}$, $\mathrm{H}_{2} \mathrm{O}_{2}$ levels were decreased by $24 \%, 29 \%$, and $39 \%$ in plants inoculated by $R$. irregularis, F. mosseae, and F. coronatum, respectively. Remarkably, under D + HS, plants inoculated with $F$. mosseae exhibited substantially reduced $\mathrm{H}_{2} \mathrm{O}_{2}$ accumulation by $63 \%$ compared with the non-inoculated plants and by $47 \%$ and $49 \%$ in plants treated by $R$. irregularis and F. coronatum, respectively.

Although under NoS, leaf MDA content did not change significantly, in both non-AM plants and AM plants, MDA increased as stress treatments were applied. AMF treatment significantly decreased MDA content compared with non-AM plants. Under the D + H stress, MDA content decreased by $27 \%, 31 \%$, and $16 \%$ in leaves, while the decreases were $14 \%, 32 \%$, and $36 \%$ under D + HS in R. irregularis, F. mosseae, and F. coronatum, respectively. In roots, AM plants showed a significant decrease in MDA levels for roots colonized by R. irregularis, F. mosseae, and F. coronatum by $25 \%, 27 \%$, and $21 \%$, respectively, under $\mathrm{D}+\mathrm{H}$ compared with the corresponding uninoculated plants. For D + HS plants, an increase in MDA level was observed in roots inoculated by F. coronatum (by $22 \%$ compared with that of non-AM roots), while no significant differences among other treatments were found.

A significant positive correlation between leaf $\mathrm{H}_{2} \mathrm{O}_{2}$ and leaf MDA was found under $\mathrm{D}+\mathrm{H}$ $\left(\mathrm{r}=0.64^{* *}\right)$, as well as between leaf $\mathrm{H}_{2} \mathrm{O}_{2}$ and root MDA $\left(\mathrm{r}=0.61^{*}\right)$ (Table S1), while under D + HS, a substantial positive correlation between leaf $\mathrm{H}_{2} \mathrm{O}_{2}$ and leaf MDA $\left(\mathrm{r}=0.89^{* * *}\right)$ and leaf MDA and root $\mathrm{H}_{2} \mathrm{O}_{2}\left(\mathrm{r}=0.70^{* *}\right)$ was also observed (Table S2).

Under different stress applications, the accumulation of $\mathrm{H}_{2} \mathrm{O}_{2}$ and MDA was higher in the leaves than in roots. However, $\mathrm{H}_{2} \mathrm{O}_{2}$ and MDA concentrations in the leaves and roots of AMF plants were lower than those of non-AM plants under combined stresses.

\subsection{Defense Enzyme Activities}

In this experiment, CAT, PPO, POD, and GST were selected, because these enzymes are known to be involved in ROS scavenging. Their activity was determined in shoots and roots of all plants for both inoculated and non-inoculated ones. Defense enzyme activity (CAT, PPO, POD, and GST) was stimulated and increased in both leaves and roots when they were exposed to the studied combined stresses. However, there was a slight difference between the inoculated and non-inoculated plants because the activity was significantly higher in mycorrhiza treated tomato plants.

No significant difference was observed in leaf POD activity among AM and non-AM plants under no stress conditions (Figure 2). POD activity significantly increased by $26 \%, 38 \%$, and $60 \%$ in plants treated with R. irregularis, F. mosseae, and F. coronatum, respectively, under D + H stress compared with the corresponding non-AM plants. Furthermore, plants inoculated with F. mosseae and F. coronatum subjected to D + HS exhibited an additional boost in the activity of POD, where it increased by $86 \%$ and $102 \%$, respectively, as compared with non-AM ones. In contrast, leaf POD drastically decreased (by $43 \%$ ) in plants colonized by $R$. irregularis, approaching the level found in non-stressed plants.

In the case of roots, there were significant $(p<0.0001)$ main effects of AM inoculation and stress applications on POD activity, and an interaction between the two main factors (Table 1). Root POD activity appeared to be consistently increased in plants under both combined stress conditions compared with that of non-stress plants (Figure 2B). POD activity was strongly enhanced in roots colonized with R. irregularis and F. coronatum under D + H (increased by $268 \%$ ) and D + HS (increased by $141 \%$ and $143 \%$, respectively) as compared with non-AM plants, while plants inoculated with $F$. mosseae showed a decrease in root POD activity by $64 \%$ under D + HS (analysis of variance (ANOVA) results are shown in Table 1).

There were significant main effects of AM inoculation and stress imposed $(p<0.0001)$ and their interaction. The imposed stresses substantially induced leaf PPO activity in plants compared with non-stress conditions (Figure 3A). The data showed no significant differences among control, R. irregularis, F. mosseae, and F. coronatum under both D + H and D + HS (Figure 3A). In roots, under D $+\mathrm{H}$, PPO activity was increased by $43 \%$ and $64 \%$ in plants treated by $R$. irregularis and F. coronatum, respectively, compared with that in non-AM plants (Figure 3B), whereas it decreased 
by $24 \%$ in plants inoculated with F. mosseae. Moreover, under D + HS, the highest root PPO activity (increased by $30 \%$ ) was in roots colonized by $R$. irregularis, while it decreased by 40 and $24 \%$ in plants inoculated with F. mosseae and F. coronatum, respectively, compared with the corresponding non-AM plants.
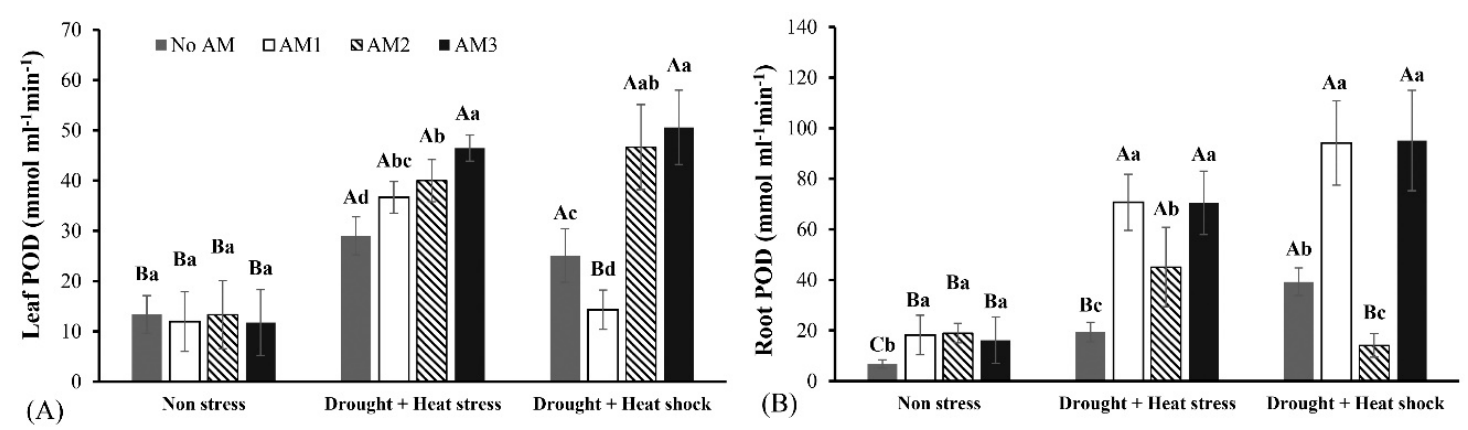

Figure 2. The activity of peroxidase (POD) in leaves (A) and roots (B) of non-inoculated plants (No AM) and plants inoculated by R. irregularis (AM1), F. mosseae (AM2), or F. coronatum (AM3) subjected to non-stress (NoS), drought + heat stress $(\mathrm{D}+\mathrm{H})$, and drought + heat shock $(\mathrm{D}+\mathrm{HS})$. Each bar represents the mean and standard deviation $(n=4)$. Different minuscules indicate significant differences among treatments under the same conditions (no stress, drought + heat stress, or drought + heat shock) by Duncan's post hoc test at $p \leq 0.05$. Different capital letters indicate significant differences of the same treatments (No AM, R. irregularis, F. mosseae, or F. coronatum) under different conditions (no stress, drought + heat stress, and drought + heat shock) by Duncan's post hoc test at $p \leq 0.05$.
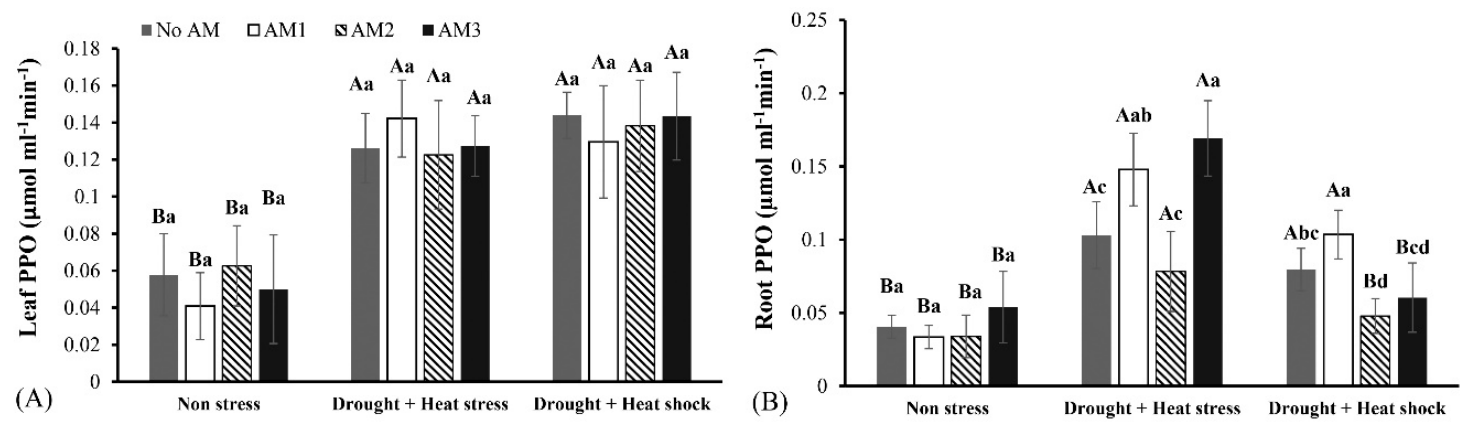

Figure 3. The activity of polyphenol oxidase (PPO) in leaves (A) and roots (B) of non-inoculated plants (No AM) and plants inoculated by R. irregularis (AM1), F. mosseae (AM2), or F. coronatum (AM3) subjected to non-stress $(\mathrm{NoS})$, drought + heat stress $(\mathrm{D}+\mathrm{H})$, and drought + heat shock $(\mathrm{D}+\mathrm{HS})$. Each bar represents the mean and standard deviation $(n=4)$. Different minuscules indicate significant differences among treatments under the same conditions (no stress, drought + heat stress, or drought + heat shock) by Duncan's post hoc test at $p \leq 0.05$. Different capital letters indicate significant differences of the same treatments (No AM, R. irregularis, F. mosseae, or F. coronatum) under different conditions (no stress, drought + heat stress, and drought + heat shock) by Duncan's post hoc test at $p \leq 0.05$.

No significant difference among treatments was observed under both no stress condition and $\mathrm{D}+\mathrm{H}$, as compared with the corresponding non-AM plants. Moreover, under D + HS, R. irregularis and F. coronatum enhanced leaf CAT activity by $42 \%$ and $57 \%$, respectively, in plants as compared with that of uncolonized plants (Figure 4A). In roots, significantly higher activity of CAT was observed in plants exposed to both stresses, compared with that of plants under no stress conditions. Under D + H stress, no significant differences in CAT activity were observed among treatments (Figure 4B), while a higher CAT activity (increased by $30 \%$ ) was observed in plants inoculated with $F$. mosseae under D + HS, while plants inoculated with $R$. irregularis and $F$. coronatum increased root CAT activity by 4 and $11 \%$, respectively, as compared with non-AM plants. There were significant impacts of AMF 
inoculation and stress imposed $(p<0.0001)$ and their interaction (Table 1$)$ on leaf CAT activity as well as on root CAT activity.
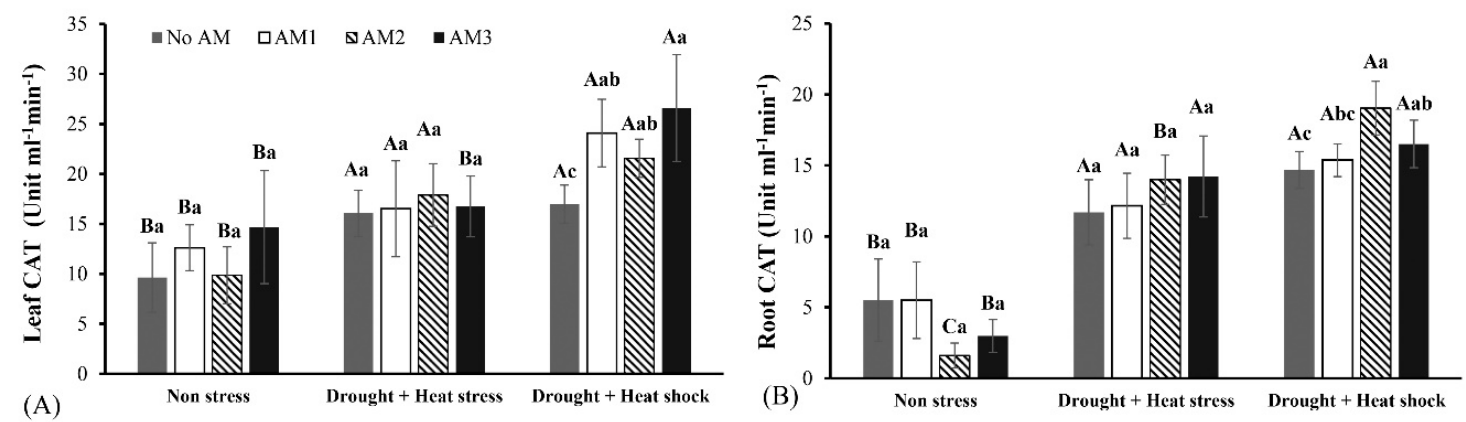

Figure 4. The activity of catalase (CAT) in leaves (A) and roots (B) of non-inoculated plants (No AM) and plants inoculated by R. irregularis (AM1), F. mosseae (AM2), or F. coronatum (AM3) subjected to non-stress (NoS), drought + heat stress $(\mathrm{D}+\mathrm{H})$, and drought+ heat shock (D+HS). Each bar represents the mean and standard deviation $(n=4)$. Different minuscules indicate significant differences among treatments under the same conditions (no stress, drought + heat stress, or drought + heat shock) by Duncan's post hoc test at $p \leq 0.05$. Different capital letters indicate significant differences of the same treatments (No AM, R. irregularis, F. mosseae, or F. coronatum) under different conditions (no stress, drought + heat stress, and drought + heat shock) by Duncan's post hoc test at $p \leq 0.05$.

Leaf glutathione-S-transferase activity was significantly increased in plants inoculated with F. mosseae compared with that of non-AM plants under NoS conditions. Moreover, the same inoculant enhanced the GST activity (increased by $46 \%$ ) in colonized plants in comparison with uninoculated plants in $\mathrm{D}+\mathrm{H}$, while the same tendency was observed in roots colonized by $\mathrm{R}$. irregularis and F. coronatum (Figure 5A). Under D + HS, no significant difference could be observed among non-AM plants and various AMF strains (R. irregularis, F. mosseae, and F. coronatum).
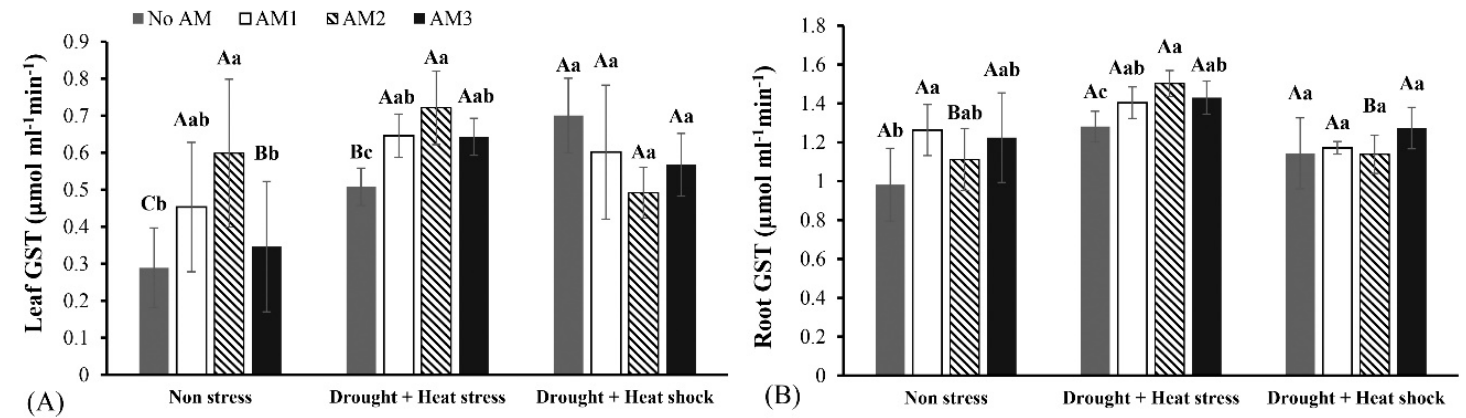

Figure 5. The activity of glutathione $S$ transferase (GST) in leaves (A) and roots (B) of non-inoculated plants (No AM) and plants inoculated by R. irregularis (AM1), F. mosseae (AM2), or F. coronatum (AM3) subjected to non-stress (NoS), drought + heat stress $(\mathrm{D}+\mathrm{H})$, and drought+ heat shock $(\mathrm{D}+\mathrm{HS})$. Each bar represents the mean and standard deviation $(n=4)$. Different minuscules indicate significant differences among treatments under the same conditions (no stress, drought + heat stress, or drought + heat shock) by Duncan's post hoc test at $p \leq 0.05$. Different capital letters indicate significant differences of the same treatments (No AM, R. irregularis, F. mosseae, or F. coronatum) under different conditions (no stress, drought + heat stress, and drought + heat shock) by Duncan's post hoc test at $p \leq 0.05$.

In roots, the two-way ANOVA test indicated a significant difference in AM inoculation, stress application, and their interaction (Table 1). A slight increase in root GST activity was determined in plants inoculated with F. mosseae, which increased by $17 \%$ compared with non-inoculated ones, while a similar trend occurred in root GST activity for both plants inoculated by R. irregularis and F. coronatum 
(increased by $8 \%$ and $22 \%$, respectively) under D $+\mathrm{H}$. Moreover, no significant impact on root GST activity was observed among non-AM plants and AM treatments under D + HS.

Under $\mathrm{D}+\mathrm{H}$ stress, arbuscular mycorrhizal colonization had a significant positive correlation with leaf GST $\left(r=0.65^{* *}\right)$, leaf POD $\left(r=0.57^{*}\right)$, root GST $\left(r=0.53^{*}\right)$, and root POD $\left(r=0.72{ }^{* *}\right)$, but had a negative correlation with leaf $\mathrm{H}_{2} \mathrm{O}_{2}\left(\mathrm{r}=-0.67^{* *}\right)$, leaf MDA $\left(\mathrm{r}=-0.76^{* * *}\right)$, $\operatorname{root} \mathrm{H}_{2} \mathrm{O}_{2}\left(\mathrm{r}=-0.69^{* *}\right)$, and root MDA $\left(\mathrm{r}=-0.66^{* *}\right)$ (Table S1), while under $\mathrm{D}+\mathrm{HS}$, a substantial positive correlation was found among AM colonization leaf CAT $\left(\mathrm{r}=0.65^{* *}\right)$ and $\operatorname{root} \mathrm{CAT}\left(\mathrm{r}=0.51^{*}\right)$, but a negative correlation was found with leaf $\mathrm{H}_{2} \mathrm{O}_{2}\left(\mathrm{r}=-0.74^{* *}\right)$, leaf MDA $\left(\mathrm{r}=-0.69^{* *}\right)$, and $\operatorname{root} \mathrm{H}_{2} \mathrm{O}_{2}\left(\mathrm{r}=-0.89^{* * *}\right)$ (Table S2).

\section{Discussion}

Combinations of drought and heat frequently occur in field conditions and under climate change, particularly in semi-arid and hot growing regions in Mexico, Argentina, North Africa, South Africa, Australia, and the Mediterranean countries, and in high latitude, semi-arid growing regions of eastern and central Asia, Kazakhstan, the USA, and Canada [39]. In the present study, we attempted to mimic the field condition of a relatively long-lasting drought period together with a short period of heat stress (heat shock), which usually takes place at mid-day (combined drought and heat shock), and the combination of a drought period with more prolonged heat stress, which is a regular occurrence in semi-arid and hot growing regions. Arbuscular mycorrhizal fungi establish mutualistic interactions with more than $80 \%$ of all plant species, providing a direct physical link between the soil and plant roots $[20,40,41]$. AMF is one of the most used biological agents in boosting plant growth, helping in photosynthesis, and enhancing tolerance to biotic and abiotic stresses [42,43]. Nevertheless, there are still gaps in our knowledge regarding the regulatory mechanisms underlying AMF mediated tolerance under combined drought and heat stresses. As the aim of this study, we examined the effects of three AMF strains on tomato plant growth and their redox status when plants are exposed to combined heat and drought $(\mathrm{D}+\mathrm{H})$ and drought and heat shock $(\mathrm{D}+\mathrm{HS})$ stress. Our results indicated that inoculation with different AMF species (R. irregularis, F. mosseae, and F. coronatum) could enhance the tolerance of combined drought and heat stress of tomato plant by improving the antioxidant enzymes system, which in turn lowered cellular $\mathrm{H}_{2} \mathrm{O}_{2}$ and decreased lipid peroxidation (MDA).

Plant biomass increase is considered the most obvious and direct feature reflecting symbiosismediated plant growth and performance under different abiotic stresses. The stimulation of plant growth by AMF under abiotic stress has been documented in various studies [44,45]. Our results revealed that different stress applications $(\mathrm{D}+\mathrm{H}$ and $\mathrm{D}+\mathrm{HS})$ impede tomato growth compared with NoS (Table 1), which might have been due to the effect on plants photosynthetic capacity, and thereby reduced stomatal conductance or the unavailability of nutrients. These results confirmed the finding of Quiroga et al. [46], who demonstrated that water deficit negatively affected the growth of drought-sensitive maize pretreated with $R$. irregularis, strain EEZ 58 (Ri), and especially in the case of drought-tolerant maize pretreated with the same strain. Moreover, limited irrigation significantly reduced the root dry weight of Medicago sativa inoculated with the mixture of $R$. intraradices and F. mosseae [13]. Contrariwise, Echinacea angustifolia seedlings inoculated with $R$. irregularis had higher dry weights than those of non-mycorrhizal seedlings under salt stress conditions [24]. On the other hand, we found that root colonization of tomato was not affected by different stress conditions $(\mathrm{D}+\mathrm{H}$ and D + HS) as compared with the non-stressed control group. This phenomenon can be attributed to the limited period of stress applications, or perhaps the different species of AMF (R. irregularis, F. mosseae, and $F$. coronatum) used in our experiment have high efficiency with tomato roots when exposed to abiotic stress conditions. Another study conducted by Boutasknit et al. [47] explained that drought does not affect root colonization because it is linked to the unchanged carbon availability of the host plant. Moreover, this finding agrees with a study conducted by Pedranzani et al. [23], where Digitaria eriantha plants were inoculated with $R$. irregularis and subjected to drought, salinity, and cold stress. In contrast, water stress decreases the root colonization of different AMF with plant species such as soybean [48], rice [49], Ocimum gratissimum [50], Trifolium repens [51], and Triticum aestivum [52]. Interestingly, Pearson 
correlation analysis in our study illustrated that mycorrhizal colonization had a close correlation with some defense enzyme activities, and a negative association with $\mathrm{H}_{2} \mathrm{O}_{2}$ and MDA levels under both combined stresses (Tables S1 and S2), highlighting the role of AMF in ROS metabolism in the host plants exposed to such simultaneous abiotic stresses.

$\mathrm{H}_{2} \mathrm{O}_{2}$ and MDA accumulation can be considered as typical criteria for assessing stress application damages, while antioxidant enzymes are one of the important features in plant defense that scavenge the harmful effects of ROS, caused by various biotic and abiotic factors. In our experiment, $\mathrm{H}_{2} \mathrm{O}_{2}$ and MDA levels were measured to investigate the effect of AMF symbiosis on stress tolerance. $\mathrm{H}_{2} \mathrm{O}_{2}$ increased sharply in the leaves of the tomato compared with the roots when subjected to different stresses, and they were significantly lower in the plants treated with different AMF species. MDA content (which is considered an end product of lipid peroxidation) decreased in plants treated with different AMF compared with non-AM plants under stress treatments (Figure 1). The MDA content was higher in leaves than in roots in all treatments. However, the higher $\mathrm{H}_{2} \mathrm{O}_{2}$ and MDA content in leaves compared with roots may be attributed to the direct exposure of leaves to light, which affects directly the photosynthesis machinery, photorespiration, and accordingly affects the mitochondria, chloroplast, and peroxisome, which are considered to be the major sites of ROS production [53,54], in contrast to the roots that lack photosynthetic activity.

Besides, our results proved the ability of AMF in lowering oxidative damages. Moreover, this is consistent with previous reports, where the reduction in $\mathrm{H}_{2} \mathrm{O}_{2}$ and MDA accumulation under different stress treatments could be explained by a significant increase in defense enzyme activities like CAT, POD, and PPO of AM plants. As compared with non-inoculated plants, concerning all treatments, the reduction of $\mathrm{H}_{2} \mathrm{O}_{2}$ and MDA can be explained by better water availability and the accumulation of osmolytes [23,27,48]. AM symbiosis decreased $\mathrm{H}_{2} \mathrm{O}_{2}$ and MDA accumulation under stress combination, identical to tomato plants under drought, heat, combined drought, and heat stress [25]. Drought-stressed trifoliate orange seedlings colonized by F. mosseae showed similar results [9]. Alleviated $\mathrm{H}_{2} \mathrm{O}_{2}$ and MDA accumulation is also correlated with stress tolerance [55]. Furthermore, we also noted higher MDA content under different stress treatments in the leaves and roots; this is coherent with the higher generation rates of $\mathrm{H}_{2} \mathrm{O}_{2}$. Previous studies have also documented this observation in plants under different stress [56].

Antioxidant enzymes are known to have prominent beneficial roles in fighting against stress conditions. In this study, combined drought and heat stress significantly stimulated the activities of antioxidant enzymes. Our results showed that mycorrhizal treatments upon different stress exposures led to a further rise (increase), decrease, or did not change the activities of GST, CAT, PPO, and POD relative to non-AM plants in leaves as well as in roots (Figures 2-5). A significant increase in leaf POD activity was found for all AMF species, except for plants treated with $R$. intraradices under combined drought and heat shock, where it has been reduced. $R$. intraradices and F. coronatum showed a much higher ability to promote POD activity in roots under both stresses. Remarkably, root PPO activity was noticeably increased by $R$. irregularis and F. coronatum upon D + HS. The change in different antioxidant enzyme activities in tomato plants in response to different stresses is related to the various forms of antioxidant enzyme metabolism; this has been proved by Sheikh Mohamadi et al. [57] using wheatgrass genotypes under drought and salinity, and is also consistent with the finding of Tommasini et al. [58] using Cenchrus ciliaris L under drought, heat, and their combination. Moreover, our results show a positive correlation between AM colonization and leaf CAT $(r=0.65 *)$ and $\operatorname{root}$ CAT $(r=0.51 *)$ (Table S2), where higher root CAT activity was found in plants inoculated with $F$. mosseae under $\mathrm{D}+\mathrm{HS}$ (Figure 4). Being a tetrameric and heme-containing enzyme, CAT catalyzes the dismutation of hydrogen-peroxide into $\mathrm{H}_{2} \mathrm{O}$ and $\mathrm{O}_{2}[59,60]$. The increase in different antioxidant enzymes shows enhanced resistance to oxidative stress-induced by drought, where the performance of AM plants differs depending on the AMF species [27,61]. The use of AMF as a biological agent is the most efficient approach to cope with the single or combined effect of drought and heat stress through the neutralization of ROS and enhancement of the antioxidant enzymes to avoid oxidative stress [25]. It is 
reported that the generation of ROS stimulates the production of abscisic acid, which plays a pivotal role in signaling networks of plant response to different abiotic stresses, which leads to the up-regulation of genes controlling the production of different antioxidants enzymes [62-65]. Our results are in accordance with other findings using different AMF and plant species such as wheat inoculated by Glomus mosseae [66]; trifoliate orange treated by F. mosseae [67]; date palm inoculated by F. mosseae [68]; finger millet inoculated with $R$. intraradices [59]; and carob inoculated with F. mosseae, Rhizophagus fasciculatus, or R. intraradices [69]. Recently, Al-Arjani et al. [70] demonstrated that AMF inoculated plants were significantly more resilient to drought stress by the upregulation of the host antioxidant defense system, especially SOD in Ephedra foliate boiss inoculated by Claroideoglomus etunicatum, $R$. intraradices, and F. mosseae. Another study illustrated that GSTs could protect the plants from different abiotic stresses [71], which have the ability to catalyze the conjugation of tripeptide glutathione (GSH) to unfamiliar electrophilic and hydrophobic substrates to form less toxic or non-toxic peptide derivatives [72]. Therefore, increased total GST enzyme and isoenzyme activity in heat stress with pre-salinity treatments according to treatment alone (salt, heat) leads to decreased hydrogen peroxide levels in maize leaves [72]; many reports illustrated that ABA induces the GST activities in different plant species under individual or combined drought and heat stress [73-76]. Hashem et al. have also reported a strong positive effect of beneficial microbes in reducing oxidative stress through the upregulation of the antioxidant system in Acacia gerrardii [17]. Cabral and coworkers found that inoculation with an AMF mixture including R. irregularis BEG140, R. irregularis, F. mosseae BEG95, F. geosporum, and Claroideoglomus claroideum in wheat (Triticum aestivum) plants mitigated the adverse effects of temperature stress at $35{ }^{\circ} \mathrm{C}$ in the daytime and $25{ }^{\circ} \mathrm{C}$ in the night for seven days [77]. Otherwise, Essahibi et al. clarified the greater capacity of carob inoculated by different AMF (F. mosseae, $R$. fasciculatus, or R. intraradices) to tolerate water stress through increased water and nutrients uptake, stomatal conductance, improved osmotic adjustment, and enhanced antioxidant system (SOD, APX, G-POD, CAT); furthermore, he recommended the use of $F$. mosseae as a biological tool to improve carob tolerance to water deficit [69].

\section{Conclusions}

The present study provides new evidence concerning the beneficial role of AMF symbiosis in the alleviation of ROS accumulation caused by combined drought and heat, and combined drought and heat shock stress. Our data revealed that the accumulation of $\mathrm{H}_{2} \mathrm{O}_{2}$ and lipid peroxidation was much higher in leaves than in roots. However, inoculation with different AMF strains, and especially, F. moseae, could enhance tomato plants' tolerance by lowering $\mathrm{H}_{2} \mathrm{O}_{2}$ and MDA content, and changed the activities of antioxidant enzymes investigated. For example, higher POD and GST activities were found in roots than in leaves of mycorrhizal plants. In contrast, higher CAT activities were found in leaves of mycorrhizal plants. However, PPO activities were not too prominent in leaves, while they increased in roots of plants inoculated by R. irregularis and F. coronatum under combined drought and heat stress. The efficiency of different AMF strains used in our experiment to endure combined drought and heat is of great importance for improving agriculture production in a vast area over the world.

Supplementary Materials: The following are available online at http://www.mdpi.com/2073-4395/10/11/1657/s1, Table S1: Pearson correlation coefficients ( $\mathrm{r}$ ) among plant physiological parameters measured under drought and heat stress $(\mathrm{D}+\mathrm{H})$; Table S2: Pearson correlation coefficients between all plant physiological parameters measured under drought and heat shock (D + HS) conditions; Figure S1: The experimental design for combined drought and heat stress $(\mathrm{D}+\mathrm{H})$ and combined drought and heat shock $(\mathrm{D}+\mathrm{HS})$ to tomato plants.

Author Contributions: I.H., E.R., N.H.D., S.T., and K.P., designed the work, carried out the experiments, analyses, interpreted all data received; P.K. and N.H.D., writing—original draft preparation; I.H. and E.R., writing一review and editing; I.H. and E.R., visualization; P.K., supervision; N.H.D., project administration; P.K., funding and acquisition. All authors have read and agreed to the published version of the manuscript.

Funding: This work was supported by Stipendium Hungaricum scholarship, by the Higher Education Institutional Excellence Program awarded by the Ministry of Human Capacities within the framework of water-related researches of Szent István University NKFIH-1159-6/2019 and GLIA: 2017-1.3.1-VKE-2017 has been implemented with the support provided from the National Research, Development, and Innovation Fund of Hungary. 
Conflicts of Interest: The author(s) declare no competing interests. All data generated or analyzed during this study are included in this published article (and its Supplementary Information files).

$\begin{array}{ll}\text { Abbreviations } & \\ \text { AM } & \text { arbuscular mycorrhizal } \\ \text { AMF } & \text { arbuscular mycorrhizal fungi } \\ \text { APX } & \text { ascorbate peroxidase } \\ \text { CAT } & \text { catalase } \\ \text { drought + heat stress } & \text { D + H } \\ \text { drought + heat shock } & \text { D + HS } \\ \text { FW } & \text { Fresh weight } \\ \text { GHS } & \text { reduced glutathione } \\ \text { GR } & \text { glutathione reductase } \\ \text { GST } & \text { glutathione-S-transferase } \\ \text { MDA } & \text { malondialdehyde } \\ \text { non-stress } & \text { NoS } \\ \text { POD } & \text { peroxidase } \\ \text { PPO } & \text { polyphenol oxidase } \\ \text { ROS } & \text { reactive oxygen species } \\ \text { SOD } & \text { superoxide dismutase }\end{array}$

\section{References}

1. Dubey, P.K.; Singh, G.S.; Abhilash, P.C. Agriculture in a changing climate. J. Clean. Prod. 2016, 113, $1046-1047$. [CrossRef]

2. Dubey, R.K.; Tripathi, V.; Dubey, P.K.; Singh, H.B.; Abhilash, P.C. Exploring rhizospheric interactions for agricultural sustainability: The need of integrative research on multi-trophic interactions. J. Clean. Prod. 2016, 115, 362-365. [CrossRef]

3. Dubey, P.K.; Singh, A. Adaptive agricultural practices for Rice-Wheat cropping system in Indo- Gangetic plains of India. Agroecosyst. Spec. Group CEM IUCN Newsl. 2017, 1, 13-17.

4. Intergovernmental Panel on Climate Change (IPCC). IPCC, 2013: Climate Change 2013: The Physical Science Basis. Contribution of Working Group I to the Fifth Assessment Report of the Intergovernmental Panel on Climate Change; Stocker, T.F., Qin, D., Plattner, G.-K., Tignor, M., Allen, S.K., Boschung, J., Nauels, A., Xia, Y., Bex, V., Midgley, P.M., Eds.; Cambridge University Press: Cambridge, UK; New York, NY, USA, 2014; 1535p.

5. Ploeg, D.V.; Heuvelink, E. Influence of sub-optimal temperature on tomato growth and yield: A review. J. Hortic. Sci. Biotechnol. 2005, 80, 652-659. [CrossRef]

6. Ideal Temperatures for Growing Tomatoes. Allot. Gard. Available online: https://www.allotment-garden. org/vegetable/how-to-grow-your-own-tomatoes/ideal-temperatures-for-growing-tomatoes/ (accessed on 13 August 2020).

7. Hameed, A.; Wu, Q.-S.; Abd-Allah, E.F.; Hashem, A.; Kumar, A.; Lone, H.A.; Ahmad, P. Role of AM Fungi in Alleviating Drought Stress in Plants. In Use of Microbes for the Alleviation of Soil Stresses: Volume 2: Alleviation of Soil Stress by PGPR and Mycorrhizal Fungi; Miransari, M., Ed.; Springer: New York, NY, USA, 2014; pp. 55-75. ISBN 978-1-4939-0721-2.

8. Osório, M.L.; Osório, J.; Vieira, A.C.; Gonçalves, S.; Romano, A. Influence of enhanced temperature on photosynthesis, photooxidative damage, and antioxidant strategies in Ceratonia siliqua L. seedlings subjected to water deficit and rewatering. Photosynthetica 2011, 49, 3-12. [CrossRef]

9. Huang, Y.-M.; Zou, Y.-N.; Wu, Q.-S. Alleviation of drought stress by mycorrhizas is related to increased root $\mathrm{H}_{2} \mathrm{O}_{2}$ efflux in trifoliate orange. Sci. Rep. 2017, 7, 42335. [CrossRef]

10. Cao, K.; Yu, J.; Xu, D.; Ai, K.; Bao, E.; Zou, Z. Exposure to lower red to far-red light ratios improve tomato tolerance to salt stress. BMC Plant Biol. 2018, 18, 92. [CrossRef]

11. Abdel Latef, A.A.H.; Mostofa, M.G.; Rahman, M.M.; Abdel-Farid, I.B.; Tran, L.-S.P. Extracts from Yeast and Carrot Roots Enhance Maize Performance under Seawater-Induced Salt Stress by Altering Physio-Biochemical Characteristics of Stressed Plants. J. Plant Growth Regul. 2019, 38, 966-979. [CrossRef] 
12. Singh, R.; Singh, S.; Parihar, P.; Mishra, R.K.; Tripathi, D.K.; Singh, V.P.; Chauhan, D.K.; Prasad, S.M. Reactive Oxygen Species (ROS): Beneficial Companions of Plants' Developmental Processes. Front. Plant Sci. 2016, 7, 1299. [CrossRef]

13. Choudhury, F.K.; Rivero, R.M.; Blumwald, E.; Mittler, R. Reactive oxygen species, abiotic stress and stress combination. Plant J. Cell Mol. Biol. 2017, 90, 856-867. [CrossRef] [PubMed]

14. Neuser, J.; Metzen, C.C.; Dreyer, B.H.; Feulner, C.; van Dongen, J.T.; Schmidt, R.R.; Schippers, J.H.M. HBI1 Mediates the Trade-off between Growth and Immunity through Its Impact on Apoplastic ROS Homeostasis. Cell Rep. 2019, 28, 1670.e3-1678.e3. [CrossRef]

15. Gill, S.S.; Tuteja, N. Reactive oxygen species and antioxidant machinery in abiotic stress tolerance in crop plants. Plant Physiol. Biochem. PPB 2010, 48, 909-930. [CrossRef]

16. Mittler, R. ROS Are Good. Trends Plant Sci. 2017, 22, 11-19. [CrossRef]

17. Hashem, A.; Abd Allah, E.F.; Alqarawi, A.A.; Al-Huqail, A.A.; Wirth, S.; Egamberdieva, D. The Interaction between Arbuscular Mycorrhizal Fungi and Endophytic Bacteria Enhances Plant Growth of Acacia gerrardii under Salt Stress. Front. Microbiol. 2016, 7, 1089. [CrossRef]

18. Wu, H.-H.; Zou, Y.-N.; Rahman, M.M.; Ni, Q.-D.; Wu, Q.-S. Mycorrhizas alter sucrose and proline metabolism in trifoliate orange exposed to drought stress. Sci. Rep. 2017, 7, 1-10. [CrossRef]

19. Horn, S.; Hempel, S.; Verbruggen, E.; Rillig, M.C.; Caruso, T. Linking the community structure of arbuscular mycorrhizal fungi and plants: A story of interdependence? ISME J. 2017, 11, 1400-1411. [CrossRef]

20. Mello, A.; Balestrini, R. Recent Insights on Biological and Ecological Aspects of Ectomycorrhizal Fungi and Their Interactions. Front. Microbiol. 2018, 9, 216. [CrossRef] [PubMed]

21. Zhao, R.; Guo, W.; Bi, N.; Guo, J.; Wang, L.; Zhao, J.; Zhang, J. Arbuscular mycorrhizal fungi affect the growth, nutrient uptake and water status of maize (Zea mays L.) grown in two types of coal mine spoils under drought stress. Appl. Soil Ecol. 2015, 88, 41-49. [CrossRef]

22. Bowles, T.M.; Jackson, L.E.; Cavagnaro, T.R. Mycorrhizal fungi enhance plant nutrient acquisition and modulate nitrogen loss with variable water regimes. Glob. Chang. Biol. 2018, 24, e171-e182. [CrossRef] [PubMed]

23. Pedranzani, H.; Rodríguez-Rivera, M.; Gutiérrez, M.; Porcel, R.; Hause, B.; Ruiz-Lozano, J.M. Arbuscular mycorrhizal symbiosis regulates physiology and performance of Digitaria eriantha plants subjected to abiotic stresses by modulating antioxidant and jasmonate levels. Mycorrhiza 2016, 26, 141-152. [CrossRef]

24. Chang, W.; Sui, X.; Fan, X.-X.; Jia, T.-T.; Song, F.-Q. Arbuscular Mycorrhizal Symbiosis Modulates Antioxidant Response and Ion Distribution in Salt-Stressed Elaeagnus angustifolia Seedlings. Front. Microbiol. 2018, 9, 652. [CrossRef] [PubMed]

25. Duc, N.H.; Csintalan, Z.; Posta, K. Arbuscular mycorrhizal fungi mitigate negative effects of combined drought and heat stress on tomato plants. Plant Physiol. Biochem. 2018, 132, 297-307. [CrossRef]

26. Xu, L.; Li, T.; Wu, Z.; Feng, H.; Yu, M.; Zhang, X.; Chen, B. Arbuscular mycorrhiza enhances drought tolerance of tomato plants by regulating the 14-3-3 genes in the ABA signaling pathway. Appl. Soil Ecol. 2018, 125, 213-221. [CrossRef]

27. Chitarra, W.; Pagliarani, C.; Maserti, B.; Lumini, E.; Siciliano, I.; Cascone, P.; Schubert, A.; Gambino, G.; Balestrini, R.; Guerrieri, E. Insights on the Impact of Arbuscular Mycorrhizal Symbiosis on Tomato Tolerance to Water Stress. Plant Physiol. 2016, 171, 1009-1023. [CrossRef] [PubMed]

28. Jia-Dong, H.; Tao, D.; Hui-Hui, W.; Ying-Ning, Z.; Qiang-Sheng, W.; Kamil, K. Mycorrhizas induce diverse responses of root TIP aquaporin gene expression to drought stress in trifoliate orange. Sci. Hortic. 2019, 243, 64-69. [CrossRef]

29. Li, J.; Meng, B.; Chai, H.; Yang, X.; Song, W.; Li, S.; Lu, A.; Zhang, T.; Sun, W. Arbuscular Mycorrhizal Fungi Alleviate Drought Stress in C3 (Leymus chinensis) and C4 (Hemarthria altissima) Grasses via Altering Antioxidant Enzyme Activities and Photosynthesis. Front. Plant Sci. 2019, 10, 499. [CrossRef] [PubMed]

30. Chu, X.T.; Fu, J.J.; Sun, Y.F.; Xu, Y.M.; Miao, Y.J.; Xu, Y.F.; Hu, T.M. Effect of arbuscular mycorrhizal fungi inoculation on cold stress-induced oxidative damage in leaves of Elymus nutans Griseb. S. Afr. J. Bot. 2016, 104, 21-29. [CrossRef]

31. Azcón, R.; del Carmen Perálvarez, M.; Roldán, A.; Barea, J.-M. Arbuscular Mycorrhizal Fungi, Bacillus cereus, and Candida parapsilosis from a Multicontaminated Soil Alleviate Metal Toxicity in Plants. Microb. Ecol. 2010, 59, 668-677. [CrossRef] 
32. Trouvelot, A.; Kough, J.; Gianinazzi-Pearson, V. Evaluation of VA infection levels in root systems. In Physiological and Genetical Aspects of Mycorrhizae; INRA Press: Paris, France, 1986; pp. 217-221.

33. Giovannetti, M.; Mosse, B. An evaluation of techniques for measuring vesicular-arbuscular mycorrhizal infection in roots. New Phytol. 1980, 84, 489-500. [CrossRef]

34. Alexieva, V.; Sergiev, I.; Mapelli, S.; Karanov, E. The effect of drought and ultraviolet radiation on growth and stress markers in pea and wheat. Plant Cell Environ. 2001, 24, 1337-1344. [CrossRef]

35. Heath, R.L.; Packer, L. Photoperoxidation in isolated chloroplasts: I. Kinetics and stoichiometry of fatty acid peroxidation. Arch. Biochem. Biophys. 1968, 125, 189-198. [CrossRef]

36. Habig, W.H.; Pabst, M.J.; Jakoby, W.B. Glutathione S-transferases. The first enzymatic step in mercapturic acid formation. J. Biol. Chem. 1974, 249, 7130-7139. [PubMed]

37. Rathmell, W.G.; Sequeira, L. Soluble peroxidase in fluid from the intercellular spaces of tobacco leaves. Plant Physiol. 1974, 53, 317-318. [CrossRef]

38. Fehrmann, H.; Diamond, A.E. Studies on Auxins in the Phytophthora Disease of the Potato Tuber I. Role of indole-acetic acid in pathogenesis. J. Phytopathol. 1967, 59, 83-100. [CrossRef]

39. Tricker, P.J.; El Habti, A.; Schmidt, J.; Fleury, D. The physiological and genetic basis of combined drought and heat tolerance in wheat. J. Exp. Bot. 2018, 69, 195-210. [CrossRef] [PubMed]

40. Coleman-Derr, D.; Tringe, S.G. Building the crops of tomorrow: Advantages of symbiont-based approaches to improving abiotic stress tolerance. Front. Microbiol. 2014, 5, 283. [CrossRef]

41. Lenoir, I.; Fontaine, J.; Lounès-Hadj Sahraoui, A. Arbuscular mycorrhizal fungal responses to abiotic stresses: A review. Phytochemistry 2016, 123, 4-15. [CrossRef]

42. Cavagnaro, T.R.; Bender, S.F.; Asghari, H.R.; Heijden, M.G.A. Van der the role of arbuscular mycorrhizas in reducing soil nutrient loss. Trends Plant Sci. 2015, 20, 283-290. [CrossRef]

43. Liu, S.; Guo, X.; Feng, G.; Maimaitiaili, B.; Fan, J.; He, X. Indigenous arbuscular mycorrhizal fungi can alleviate salt stress and promote growth of cotton and maize in saline fields. Plant Soil 2016, 398, 195-206. [CrossRef]

44. Mo, Y.; Wang, Y.; Yang, R.; Zheng, J.; Liu, C.; Li, H.; Ma, J.; Zhang, Y.; Wei, C.; Zhang, X. Regulation of Plant Growth, Photosynthesis, Antioxidation and Osmosis by an Arbuscular Mycorrhizal Fungus in Watermelon Seedlings under Well-Watered and Drought Conditions. Front. Plant Sci. 2016, 7, 644. [CrossRef]

45. Ye, L.; Zhao, X.; Bao, E.; Cao, K.; Zou, Z. Effects of Arbuscular Mycorrhizal Fungi on Watermelon Growth, Elemental Uptake, Antioxidant, and Photosystem II Activities and Stress-Response Gene Expressions Under Salinity-Alkalinity Stresses. Front. Plant Sci. 2019, 10, 863. [CrossRef]

46. Quiroga, G.; Erice, G.; Aroca, R.; Chaumont, F.; Ruiz-Lozano, J.M. Enhanced Drought Stress Tolerance by the Arbuscular Mycorrhizal Symbiosis in a Drought-Sensitive Maize Cultivar Is Related to a Broader and Differential Regulation of Host Plant Aquaporins than in a Drought-Tolerant Cultivar. Front. Plant Sci. 2017, 8, 1056. [CrossRef] [PubMed]

47. Boutasknit, A.; Baslam, M.; Ait-El-Mokhtar, M.; Anli, M.; Ben-Laouane, R.; Douira, A.; El Modafar, C.; Mitsui, T.; Wahbi, S.; Meddich, A. Arbuscular Mycorrhizal Fungi Mediate Drought Tolerance and Recovery in Two Contrasting Carob (Ceratonia siliqua L.) Ecotypes by Regulating Stomatal, Water Relations, and (In)Organic Adjustments. Plants 2020, 9, 80. [CrossRef] [PubMed]

48. Porcel, R.; Ruiz-Lozano, J.M. Arbuscular mycorrhizal influence on leaf water potential, solute accumulation, and oxidative stress in soybean plants subjected to drought stress. J. Exp. Bot. 2004, 55, 1743-1750. [CrossRef]

49. Ruíz-Sánchez, M.; Armada, E.; Muñoz, Y.; García de Salamone, I.E.; Aroca, R.; Ruíz-Lozano, J.M.; Azcón, R. Azospirillum and arbuscular mycorrhizal colonization enhance rice growth and physiological traits under well-watered and drought conditions. J. Plant Physiol. 2011, 168, 1031-1037. [CrossRef]

50. Hazzoumi, Z.; Moustakime, Y.; hassan Elharchli, E.; Joutei, K.A. Effect of arbuscular mycorrhizal fungi (AMF) and water stress on growth, phenolic compounds, glandular hairs, and yield of essential oil in basil (Ocimum gratissimum L.). Chem. Biol. Technol. Agric. 2015, 2, 10. [CrossRef]

51. Tuo, X.-Q.; He, L.; Zou, Y.-N. Alleviation of Drought Stress in White Clover after Inoculation with Arbuscular Mycorrhizal Fungi. Not. Bot. Horti Agrobot. Cluj Napoca 2017, 45, 220-224. [CrossRef]

52. Mathur, S.; Tomar, R.S.; Jajoo, A. Arbuscular Mycorrhizal fungi (AMF) protects photosynthetic apparatus of wheat under drought stress. Photosynth. Res. 2019, 139, 227-238. [CrossRef]

53. Apel, K.; Hirt, H. Reactive oxygen species: Metabolism, oxidative stress, and signal transduction. Annu. Rev. Plant Biol. 2004, 55, 373-399. [CrossRef] 
54. Foyer, C.H.; Noctor, G. Oxidant and antioxidant signalling in plants: A re-evaluation of the concept of oxidative stress in a physiological context. Plant Cell Environ. 2005, 28, 1056-1071. [CrossRef]

55. Mirshad, P.P.; Puthur, J.T. Arbuscular mycorrhizal association enhances drought tolerance potential of promising bioenergy grass (Saccharum arundinaceum retz.). Environ. Monit. Assess. 2016, 188, 425. [CrossRef]

56. Ara, N.; Nakkanong, K.; Lv, W.; Yang, J.; Hu, Z.; Zhang, M. Antioxidant enzymatic activities and gene expression associated with heat tolerance in the stems and roots of two cucurbit species ("Cucurbita maxima" and "Cucurbita moschata") and their interspecific inbred line "Maxchata". Int. J. Mol. Sci. 2013, 14, 24008-24028. [CrossRef]

57. Sheikh-Mohamadi, M.H.; Etemadi, N.; Nikbakht, A.; Arab, M.; Majidi, M.M.; Pessarakli, M. Antioxidante defence system and physiological responses of Iranian crested wheatgrass (Agropyron cristatum L.) to drought and salinity stress. Acta Physiol. Plant. 2017, 39, 245. [CrossRef]

58. Tommasino, E.; López Colomba, E.; Carrizo, M.; Grunberg, K.; Quiroga, M.; Carloni, E.; Griffa, S.; Ribotta, A.; Luna, C. Individual and combined effects of drought and heat on antioxidant parameters and growth performance in Buffel grass (Cenchrus ciliaris L.) genotypes. S. Afr. J. Bot. 2018, 119, 104-111. [CrossRef]

59. Sofo, A.; Scopa, A.; Nuzzaci, M.; Vitti, A. Ascorbate peroxidase and catalase activities and their genetic regulation in plants subjected to drought and salinity stresses. Int. J. Mol. Sci. 2015, 16, 13561-13578. [CrossRef] [PubMed]

60. Zhao, H.; Yi, X.; Hu, Z.; Hu, M.; Chen, S.; Dong, X.; Gong, L. RNAi-mediated knockdown of catalase causes cell cycle arrest in SL-1 cells and results in low survival rate of Spodoptera litura (Fabricius). PLoS ONE 2013, 8, e59527. [CrossRef]

61. Tyagi, J.; Varma, A.; Pudake, R.N. Evaluation of comparative effects of arbuscular mycorrhiza (Rhizophagus intraradices) and endophyte (Piriformospora indica) association with finger millet (Eleusine coracana) under drought stress. Eur. J. Soil Biol. 2017, 81, 1-10. [CrossRef]

62. Xu, Y.; Fu, J.; Chu, X.; Sun, Y.; Zhou, H.; Hu, T. Nitric oxide mediates abscisic acid induced light-tolerance in leaves of tall fescue under high-light stress. Sci Hortic. 2013, 162, 1-10. [CrossRef]

63. Zhang, X.H.; Liu, Y.H.; Liu, B.W.; Liu, Q.; Wen, S.Y.; Ao, B.; Lin, Z.Q.; Zheng, Y.L.; Yang, W.Z.; Chu, X.T.; et al. Arbuscular mycorrhiza fungus improved growth, antioxidant defense, and endogenous hormones in tall fescue under low-light stress. S. Afr. J. Bot. 2019, 127, 43-50. [CrossRef]

64. Sattar, A.; Sher, A.; Ijaz, M.; Ul-Allah, S.; Rizwan, M.S.; Hussain, M.; Jabran, K.; Cheema, M.A. Terminal drought and heat stress alter physiological and biochemical attributes in flag leaf of bread wheat. PLoS ONE 2020, 15, e0232974. [CrossRef]

65. Guajardo, E.; Correa, J.A.; Contreras-Porcia, L. Role of abscisic acid (ABA) in activating antioxidant tolerance responses to desiccation stress in intertidal seaweed species. Planta 2016, 243, 767-781.

66. Rani, B.; Madan, S.; POOJA, K.S.; Sharma, K.D.; Kumari, N.; Kumar, A. Mitigating the effect of drought stress on yield in wheat (Triticum aestivum) using arbuscular mycorrhiza fungi (Glomus mosseae). Indian J. Agric. Sci. 2018, 88, 95-100.

67. Huang, Y.-M.; Srivastava, A.K.; Zou, Y.-N.; Ni, Q.-D.; Han, Y.; Wu, Q.-S. Mycorrhizal-induced calmodulin mediated changes in antioxidant enzymes and growth response of drought-stressed trifoliate orange. Front. Microbiol. 2014, 5, 682.

68. Benhiba, L.; Fouad, M.O.; Essahibi, A.; Ghoulam, C.; Qaddoury, A. Arbuscular mycorrhizal symbiosis enhanced growth and antioxidant metabolism in date palm subjected to long-term drought. Trees 2015, 29, 1725-1733.

69. Essahibi, A.; Benhiba, L.; Babram, M.A.; Ghoulam, C.; Qaddoury, A. Influence of arbuscular mycorrhizal fungi on the functional mechanisms associated with drought tolerance in carob (Ceratonia siliqua L.). Trees 2018, 32, 87-97.

70. Al-Arjani, A.-B.F.; Hashem, A.; Abd_Allah, E.F. Arbuscular mycorrhizal fungi modulates dynamics tolerance expression to mitigate drought stress in Ephedra foliata Boiss. Saudi J. Biol. Sci. 2020, 27, 380-394. [CrossRef]

71. Ding, N.; Wang, A.; Zhang, X.; Wu, Y.; Wang, R.; Cui, H.; Huang, R.; Luo, Y. Identification and analysis of glutathione S-transferase gene family in sweet potato reveal divergent GST-mediated networks in aboveground and underground tissues in response to abiotic stresses. BMC Plant Biol. 2017, 17, 225.

72. Cetinkaya, H.; Tasci, E.; Dinler, B.S. Regulation of glutathione S-transferase enzyme activity with salt pre-treatment under heat stress in maize leaves. Res. Plant Biol. 2014, 4, 45-56. 
73. Kellős, T.; Tímár, I.; Szilágyi, V.; Szalai, G.; Galiba, G.; Kocsy, G. Stress hormones and abiotic stresses have different effects on antioxidants in maize lines with different sensitivity. Plant Biol. 2008, 10, 563-572.

74. Halušková, L.; Valentovičová, K.; Huttová, J.; Mistrík, I.; Tamás, L. Effect of abiotic stresses on glutathione peroxidase and glutathione S-transferase activity in barley root tips. Plant Physiol. Biochem. 2009, 47, 1069-1074.

75. Jiang, H.-W.; Liu, M.-J.; Chen, I.-C.; Huang, C.-H.; Chao, L.-Y.; Hsieh, H.-L. A Glutathione S-Transferase Regulated by Light and Hormones Participates in the Modulation of Arabidopsis Seedling Development. Plant Physiol. 2010, 154, 1646-1658. [CrossRef] [PubMed]

76. Liu, T.; Zhang, L.; Yuan, Z.; Hu, X.; Lu, M.; Wang, W.; Wang, Y. Identification of proteins regulated by ABA in response to combined drought and heat stress in maize roots. Acta Physiol. Plant 2013, 35, 501-513. [CrossRef]

77. Cabral, C.; Ravnskov, S.; Tringovska, I.; Wollenweber, B. Arbuscular mycorrhizal fungi modify nutrient allocation and composition in wheat (Triticum aestivum L.) subjected to heat-stress. Plant Soil 2016, 408, 385-399. [CrossRef]

Publisher's Note: MDPI stays neutral with regard to jurisdictional claims in published maps and institutional affiliations.

(C) 2020 by the authors. Licensee MDPI, Basel, Switzerland. This article is an open access article distributed under the terms and conditions of the Creative Commons Attribution (CC BY) license (http://creativecommons.org/licenses/by/4.0/). 